\title{
PROPAGATION OF ACOUSTIC WAVES GENERATED IN THIN FILMS BY LASER RADIATION
}

\author{
D. MAKSIMOVIĆ, J. MOŽINA and M. TERZIĆ* \\ University of Ljubljana, Faculty of Mechanical Engineering, P.O. Box 394, YU-61000 Ljubljana, \\ Yugoslavia \\ *University of Novi Sad, Institute of Physics, P.O. Box 224, YU-21000 Novi Sad, Yugoslavia
}

We demonstrate here a method using a laser probe ${ }^{1,2}$ to study the dynamics of propagation of acoustic waves generated at the surface of a $\mathrm{Cr}$ thin film $80 \mathrm{~nm}$ thick on a glass substrate. The detected pulse shapes of the acoustic waves produced by Nd:YAG laser $(1.06 \mu \mathrm{m})$ yielding 30 $\mathrm{mJ} / \mathrm{pulse}$, show that the generating processes and consequently the laser-film interaction are nonlinear.

Having in mind the fact that the thermal features of the thin film considerably influence the photoacoustic signal, the obtained results could be used to evaluate the thermal features of the thin film as well as to better understand the interaction of laser radiation with matter. Special attention will be given to evaluate the velocity of the acoustical waves propagating from the wave source in the film plane and perpendicularly to it.

References

1. A. C. Boccara, D. Fournier, J. Badoz, Appl. Phys. Lett., 36, 130 (1980)

2. L. C. Aamodt, J. C. Murphy, J. Appl. Phys., 54, 581 (1983) 